INTERNATIONAL JOURNAL OF RESEARCHES IN BIOSCIENCES, AGRICULTURE AND TECHNOLOGY (C) VISHWASHANTI MULTIPURPOSE SOCIETY (Global Peace Multipurpose Society) R. No. MH-659/13(N) www.ijrbat.in

\title{
GREEN SYNTHESIS AND CHARACTERIZATION OF GOLD NANOPARTICLES USING EPIPHYTIC PLANTS ACAMPE PRAEMORSA LEAVES EXTRACT AND EVALUATION OF THEIR ANTIBACTERIAL ACTIVITIES.
}

\author{
Prita Pillai \\ S.V.R.N.S.S College Vazhoor, \\ Theerthapadapuram (PO), Vazhoor, Kottayam Kerala-686505
}

\begin{abstract}
:
The biosynthesis, characterization and application of biologically synthesized gold nanoparticles are the important aspects of nanotechnology. Nanotechnology deals with the nanoparticles having size from 1-100nm in one dimension. In this investigation green synthesis of gold nanoparticles obtained from $\mathrm{HAuCl}_{4}(1 \mathrm{mM})$ solution through the aqueous leaves extract of Acampe praemorsa. The aqueous $\mathrm{Au}^{3+}$ ions reacted with the broth of leaf extracts, which were reduced and resulted as gold nanoparticles $\mathrm{Au}^{\circ}$ and the colour change proves the first indication of the formation of nanoparticles. Further the characterization of bio reduced nanoparticles observed by UV-Vis absorption spectroscopy, FTIR [Fourier Transform Infrared Spectroscopy] and SEM [Scanning Electron Microscopy]. The gold nanoparticles synthesized via green route are highly toxic to multidrug resistant pathogens, hence it has a great potential in biomedical applications. Later these biologically synthesized nanoparticles exhibited for antibacterial activity. The antibacterial activities were carried out against E.coli strain by using well diffusion methods.
\end{abstract}

Keywords: Gold nanoparticles, Acampe praemorsa leaves extract, UV-vis spectroscopy, FTIR, SEM, Antibacterial activity.

\section{INTRODUCTION:}

Nanotechnology is an escalating field of Modern Research with desired application in electronics and medicine. Nanotechnology involves the synthesis of nanoparticles of size ranging from 1 to $100 \mathrm{~nm}$. Nanotechnology represents an economic alternative for chemical and physical method of nanoparticles formation. The physical and chemical synthesis of nanoparticles can be toxic and highly reactive posing a risk to the environment and human or the procedures are too expensive to be feasible at an industrial scale. Therefore there has been a search for inexpensive, reliable, safe and "green" approach to synthesize stable metal nanoparticles with controlled size and shape. Plant mediated biological synthesis of nanoparticles is gaining importance due to its simplicity and eco-friendliness. The biosynthesis of nanoparticles by plants such as Terminalia catappa [Ankamwar B et al., 2010], Camelia sinensis [Nune S K et al., 2009], Lemon grass [Shiv S S et al., 2004], Allium cepa [Umesh kumar parida et al., 2011] has been reported. Biological approaches using microorganisms and plants or plant extracts for metal nanoparticles synthesis have been suggested as valuable alternative to chemical methods [Sastry M. et al., 2004]. Nano crystalline gold particles have found tremendous applications in the field of highly sensitivity bio molecular detection and diagnostics [Vaidyanathan R et al., 2009]. This is because of the unique physiochemical characteristics of nanoparticles including catalytic activity, optical properties, electronic properties, antibacterial and magnetic properties [Rajasulochana P et al., 2010]. The rapid formation of stable Au nanoparticles has been found using Galaxaura elongatain aqueous medium at normal atmospheric condition TEM analysis revealed that the particles are spherical in shape along with a few triangular, truncated, hexagonal shape nanoparticles. FTIR showed that nanoparticles were capped by algal compounds [Singaravelu et al., 2013]. Amaranthus spinosus investigated for toxicity of the synthesized gold nanoparticles and found non toxic to the cancer cell lines and could be used for bio medical applications [Ratul Kumar Das et al., 2012]. Biological approach 
is the most suitable way for the synthesis of gold nanoparticles [Ahmad et al., 2003]. This work discusses about the extraction of gold nanoparticles from epiphytic plant; Acampe praemorsa and their antimicrobial activity. These plants have medicinal uses and significant anti-inflammatory activities. The aim of the present work is- To biosynthesise gold nanoparticles using aqueous leaves extract of Acampe praemorsa. To characterize the gold nanoparticles by using UV-Vis spectroscopy, FTIR and SEM, To analyze antibacterial properties of Acampe praemorsa against E.coli bacteria.

\section{METHOD AND MATERIAL:}

Fresh leaves of the plants were collected from the campus of S.V.R.N.S.S College, Vazhoor. The collected leaves where washed with sterile distilled water and used for extract preparation. About $10 \mathrm{~g}$ of fresh leaves were weighed, cut in to small pieces and crushed in to $100 \mathrm{ml}$ distilled water with the help of mortar and pestle. Then the mixture is filtered through Whatman No.1 filter paper.1 $\mathrm{mM}$ aqueous solution of $\mathrm{HAuCl}_{4}$ was prepared and used for the synthesis of gold nanoparticles. $\mathrm{HAuCl}_{4}$ was obtained from Sigma Aldrich and used as without further purification. $10 \mathrm{ml}$ of aqueous leaves extract was added in to $90 \mathrm{ml}$ aqueous solution of $1 \mathrm{mM} \mathrm{HAuCl}_{4}$ [1:9] for bio reduction in to gold ions $\left[\mathrm{Au}^{3+} \rightarrow \mathrm{Au}^{\circ}\right]$ allow to react at ambient conditions.

Characterization of gold nanoparticles monitored through UV-vis spectra analysis. The chemical composition and bio reduced gold ions in aqueous solution was monitored by periodic sampling of 3$5 \mathrm{ml}$ solution and subsequently measuring UV-vis spectra of the solution at 300-700nm. The FTIR spectrum was used to analyze the functional group present in the epiphytic plant leaves extract. The samples for FTIR analysis was prepared by mixing plant extracts with $1 \mathrm{mM} \mathrm{HAuCl} \mathrm{m}_{4}$. The samples were scanned using infrared in range of $4000-1000 \mathrm{~cm}^{-}$ ${ }^{1}$ using FTIR. The SEM images provided information about the morphology and size of the bio synthesized gold nanoparticles. The gold nanoparticles found to be oval or spherical in shape. Antibacterial activity carried out by agar- well diffusion method. Petri plates containing $20 \mathrm{ml}$ Muller Hinton medium were seeded with $24 \mathrm{hr}$ culture of bacterial strains such as E.coli. wells of approximately $10 \mathrm{~mm}$ was bored using a well cutter and sample of $50 \mu 1$ and $100 \mu 1$ Concentration were added. The plates were then incubated at $37^{\circ} \mathrm{C}$ for $24 \mathrm{hr}$. The antibacterial activity was assayed by measuring the diameter of the inhibitions zone formed around the well (NCCLS, 1993). Streptomycin was used as a positive control.

\section{RESULTS AND DISCUSSION}

The green synthesis of gold nanoparticles occurred during the exposure of epiphytic leaves extract to $1 \mathrm{mM} \mathrm{HAuCl} \mathrm{H}_{4}$ aqueous solution. The complete reduction of gold ions was observed after 2-3 hours. The colour change in the reaction mixture was observed during the incubation period, because the formation of gold nanoparticles is able to produce a particular colour in the reaction mixture due to their specific properties.

Visual observation of gold nanoparticles confirmed through the development of greenish aqueous suspension to ruby red colour due to the reduction of gold ions (fig2). This is the visual indication of formation of gold nanoparticles.

The periodic scan of optical absorbance between $300-700 \mathrm{~nm}$ with a UV-Vis spectrophotometer at resolution of $1 \mathrm{~nm}$ were performed to investigate the reduction rate of gold ions by Acampe praemorsa leaves extract. The reduction mixture was used for UV-Vis analysis, so the UV-Vis spectroscopy revealed the presence of gold nanoparticles. Absorption spectra of gold nanoparticles formed in Acampe praemorsa extract had absorbance peak at $555 \mathrm{~nm}$ (fig.3).

FTIR analysis confirmed that the bio reduction of gold ions to gold nanoparticles is due to the reduction by capping materials of plant extract. The synthesized gold nanoparticles were confirmed by 
changes that occurred in the FTIR spectra after synthesis. In Acampe praemorsa FTIR absorption spectra of bio reduction of gold ions observed by the absorption bands of the region of $4000-1000 \mathrm{~cm}^{-1}$ are 4411.2, 4220.25, 3716.83, 3057.17, 2956.87, 2924.09, 2852.72, 2374.37, 1905.67, 1745.58 \& $725.23 \mathrm{~cm}^{-1}$ (fig. 4). The bio reduced nanoparticles are the result of the bio reduction of plant extract and the capping agent which is present in the extract.

The SEM images provided information about the morphology and size of the bio synthesized gold nanoparticles. The gold nanoparticles found to be spherical and cubic in shape, the diameter of gold nanoparticles was identified by SEM analysis. Further the SEM images showed the high density gold nanoparticles synthesized by Acampe praemorsa leaves extract. In Acampe praemorsa the SEM images showing the size of gold nanoparticles between the range from $5 \mu-10 \mu$ under the magnification range of 3000. (Fig.- 5).

Bactericidal effect seen on Hospital strain E.coli of Gold nanoparticles synthesized by Acampe praemors leaf extracts and showed synergetic effect with Streptomycin. Synthesized Gold nanoparticle shows zone of inhibition against the entire tasked microorganism. Zone of inhibition for Acampe praemorsa was found from the range of $8 \mathrm{~mm}$ and $12 \mathrm{~mm}$ with $50 \mu \mathrm{l}$ and $100 \mu \mathrm{l}$ concentrations respectively against E.coli and its zone was $20 \mathrm{~mm}$. Synergetic effect of Gold nanoparticles concentration against E.coli was found prominent than the effect of antibiotic alone. (Fig.- 6 ).

\section{CONCLUSION:}

It is an economic alternative for chemical and physical method of nanoparticles formation by biological approach using plant extract. In this work epiphytic plant leaves extract were effectively used in the synthesis of gold nanoparticles as a greener route. The reduction of gold ions led to the formation of gold nanoparticles of fairly well defined dimensions using Acampe praemorsa leaves extract. Further the bio synthesized gold nanoparticles revealed to possess an effective anti bacterial property against E.coli. The present study emphasizes the use of these plants for the synthesis and characterization of gold nanoparticles with potent antibacterial effect. The green synthesis method is eco friendly, cost effective and easily scaled up to large scale synthesis. Following the addition of epiphytic leaf extracts to aqueous $\mathrm{HAuCl}_{4}$ solution, gold nanoparticles began to form within 10 minutes and the reaction neared completion at 2-3 hours. Observation of gold nanoparticles confirmed through the development of greenish aqueous suspension to ruby red colour due to the reduction of gold ions. UV-Vis spectroscopy revealed the presence of gold nanoparticles. Absorption spectra of gold nanoparticles formed in the reaction medium which had absorbance peak at $555 \mathrm{~nm}$ in Acampe praemorsa. The FTIR value showed the reduction and capping agent of gold ions from 4411.2 to $725.23 \mathrm{~cm}^{-1}$. The SEM images showing the size of gold nanoparticles between the range from $5 \mu-10 \mu$ under the magnification range of 3000 in Acampe praemorsa. The bactericidal effect were also seen on Hospital strain E.coli of Gold nanoparticles synthesized by Acampe praemorsa leaf extracts. Zone of inhibition for Acampe praemorsa was found from the range of $8 \mathrm{~mm}$ and $12 \mathrm{~mm}$ with $50 \mu \mathrm{l}$ and $100 \mu \mathrm{l}$ concentrations.

\section{REFERANCE :}

Ahmad,A.M.P.;Senapati,S.;Mandal,D.;Khan,M.I.;Kum ar,R.\&Sastry,M. (2002), Extracellular biosynthesis of silver nanoparticles using the fungus Fusarium oxysporum. Colloids and surfaces B: Bio interfaces,.28:P.313-318.

B. Ankamwar, (2010), Bio synthesis of gold nanoparticles (Green Gold) using leaf extract of Terminalia catappa E-journal of chemistry, vol.7, No.4, PP.1334-1339.

National Committee for Clinical Laboratory Standards, (1993), Performance Standards for 
Antimicrobial Disk Susceptibility Tests-Fifth Edition: Approved Standard M2-A5. NCCLS, Villanova, P A.

Rajasulochana P, Dhamotharan R, Murugakoothan P, Murugesan S, Krishnamoorthy P, (2010), Biosynthesis and characterization of gold nanoparticles using the algae Kappaphycus alvarezii. International journal of Nanoscience 9(5): 511-516.

Ratul Kumar Das, Nayanmoni Gogoi, Punuri jayasekhar Babu, Pragya Sharma Chandan Mahanta, Utpal Bora, (2012), The synthesis of gold nanoparticles using Amaranthus spinosus leaf extract and study of their optical properties. Advances in materials physics and chemistry, Vol.2, PP., 275-281.

S.K Nune, N.Chanda, R.Shukla, K.Katti, R.R. Kulkarni, S. Thilakavathy, S. Mekapothula, R. Kannan and K.V. Katti, (2009), A Green Nanotechnology from Tea: phytochemicals in tea as building blocks for production of bio compactable Gold nanoparticles, Journal of materials chemistry Vol.10,P.1039.

S.S Shiv, A. Rai, B. Ankamwar, A.Singh, A.Ahmad and M. Sastry, (2004), Biological synthesis of triangular gold nanoprisms. Nature materials Vol.3, PP. 482-488.

Sastry,M; Ahmad, A.; Khan M.I.; Kumar, R. Nie Meyer, C.M., Mirkin, C.A., Wiley-vcH: (2004), Green synthesis of gold nanoparticles using fruit extract of Ananas comosus and evaluation of biological activities, Eds.; Wein Heim, Germany..126.

Singaravelan, J.S Arokia Mary, V.G Kumar, K.Govindaraju, (2013), Green biosynthesis of gold nanoparticles using Galaxura elongata and characterization of their antibacterial activity. Colloids surf. B, Vol. 57, PP. 97-101.

Umesh Kumar Parida, Birendra Kumar Bindhani, Padmalochan Nayak (2011), Green synthesis and characterization of gold nanoparticles using onion (Allium cepa) extract. Wond
Journal of nano science and Engineering Vol.1, PP.93-98.

Vaidyanathan R, Kalishwaralal K, Gopalram S, Gurunathan S (2009), Nanosilver: the burgeoning therapeutic molecules and its green synthesis. Biotechnology Adv; 27:924937.

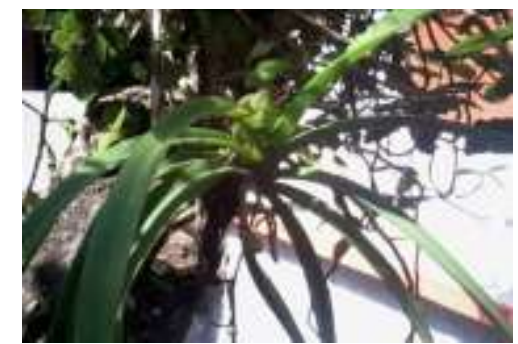

Fig.1. Acampe praemorsa- Family: Orchidaceae

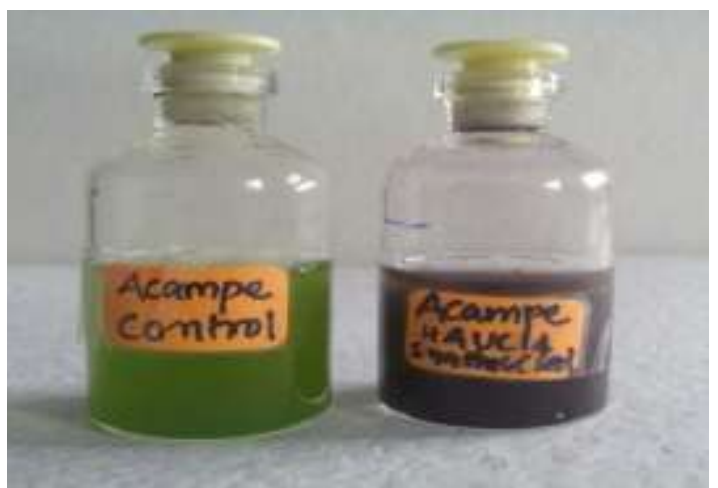

Fig-2. Acampe praemorsa leaves extract as control and bio reduction of gold nanoparticles as ruby red colour.

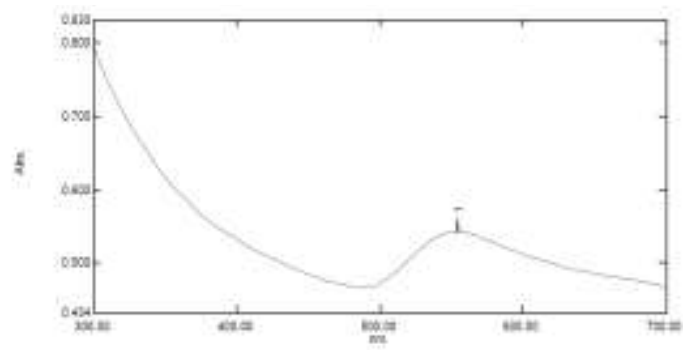

Fig-3. UV-Vis analysis Acampe praemorsa leaves extract 


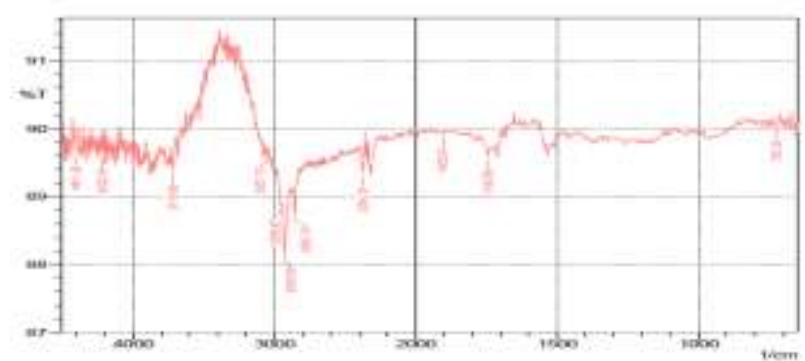

Fig-4. FTIR analysis of Acampe praemorsa leaves extract

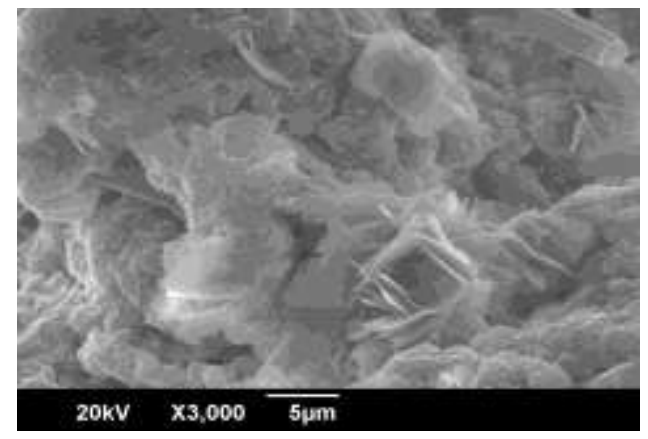

Fig-5. SEM images of Acampe praemorsa.
Fig-6. Antibacterial activity of Acampe praemorsa Gold nanoparticles against E.coli

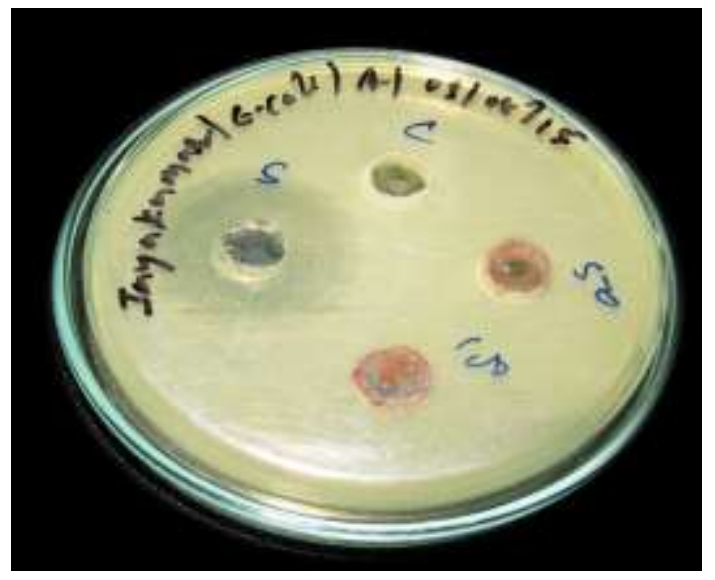

